Article

\title{
Low Sensitivity of Real Time PCRs Targeting Retrotransposon Sequences for the Detection of Schistosoma japonicum Complex DNA in Human Serum
}

\author{
Hagen Frickmann ${ }^{1,2, *}+\dagger^{(D)}$, Ulrike Loderstädt ${ }^{3,+}$, Beatrice Nickel ${ }^{4,5}$, Sven Poppert ${ }^{4,5}$, Peter Odermatt ${ }^{4,5}$, \\ Somphou Sayasone ${ }^{6}$, Marjan Van Esbroeck ${ }^{7}$ (D), Isabel Micalessi ${ }^{7}$, Lieselotte Cnops ${ }^{7}$, Poom Adisakwattana ${ }^{8}$, \\ Gérard Leboulle ${ }^{9}$, Olfert Landt ${ }^{9}$, Thorsten Thye ${ }^{10}$ and Egbert Tannich ${ }^{11, *}$
}

check for updates

Citation: Frickmann, H.; Loderstädt, U.; Nickel, B.; Poppert, S.; Odermatt, P.; Sayasone, S.; Van Esbroeck, M.; Micalessi, I.; Cnops, L.; Adisakwattana, P.; et al. Low Sensitivity of Real Time PCRs Targeting Retrotransposon Sequences for the Detection of Schistosoma japonicum Complex DNA in Human Serum. Pathogens 2021, 10, 1067. https://doi.org/10.3390/ pathogens 10081067

Academic Editor: Collette Bromhead

Received: 27 July 2021

Accepted: 19 August 2021

Published: 22 August 2021

Publisher's Note: MDPI stays neutral with regard to jurisdictional claims in published maps and institutional affiliations.

Copyright: (c) 2021 by the authors. Licensee MDPI, Basel, Switzerland. This article is an open access article distributed under the terms and conditions of the Creative Commons Attribution (CC BY) license (https:/ / creativecommons.org/licenses/by/ $4.0 /)$.
1 Department of Microbiology and Hospital Hygiene, Bundeswehr Hospital Hamburg, 20359 Hamburg, Germany

2 Department of Medical Microbiology, Virology and Hygiene, University Medicine Rostock, 18057 Rostock, Germany

3 Department of Hospital Hygiene \& Infectious Diseases, University Medicine Göttingen, 37075 Göttingen, Germany; ulrike.loderstaedt1@med.uni-goettingen.de

4 Swiss Tropical and Public Health Institute, 4051 Basel, Switzerland; beatrice.nickel@swisstph.ch (B.N.) sven@poppert.eu (S.P.); peter.odermatt@swisstph.ch (P.O.)

5 University of Basel, 4001 Basel, Switzerland

6 Lao Tropical and Public Health Institute, Vientiane Capital 01000, Laos; somphou.sayasone@yahoo.com

7 Department of Clinical Sciences, Institute of Tropical Medicine, 2000 Antwerp, Belgium; mvesbroeck@itg.be (M.V.E.); imicalessi@itg.be (I.M.); lcnops@itg.be (L.C.)

8 Department of Helminthology, Faculty of Tropical Medicine, Mahidol University, Bangkok 10400, Thailand; poom.adi@mahidol.edu

9 TIB MOLBIOL, 12103 Berlin, Germany; gleboulle@tib-molbiol.de (G.L.); olandt@tib-molbiol.de (O.L.)

10 Department Infectious Disease Epidemiology, Bernhard Nocht Institute for Tropical Medicine Hamburg, 20359 Hamburg, Germany; thye@bnitm.de

11 National Reference Centre for Tropical Pathogens, Bernhard Nocht Institute for Tropical Medicine Hamburg, 20359 Hamburg, Germany

* Correspondence: frickmann@bnitm.de (H.F.); tannich@bnitm.de (E.T.); Tel.: +49-40-6947-28743 (H.F.); +49-40-42828-260 (E.T.)

† Hagen Frickmann and Ulrike Loderstädt contributed equally to this work.

Abstract: While hybridization probe-based real-time PCR assays targeting highly repetitive multicopy genome sequences for the diagnosis of $S$. mansoni complex or S. haematobium complex from human serum are well established, reports on the evaluation of respective assays for the identification of $S$. japonicum complex DNA in human serum are scarce. Here, we assessed the potential use of the retrotransposon sequences SjR2 and SjCHGCS19 from S. japonicum, S. mekongi and S. malayensis for the diagnosis of Asian Schistosoma infections. Based on available S. japonicum sequences and newly provided S. mekongi and S. malayensis sequences, hybridization probe-based real-time PCRs targeting SjR2 and SjCHGCS19 of the S. japonicum complex were designed both as consensus primer assays as well as multi-primer assays for the coverage of multiple variants of the target sequences. The assays were established using plasmids and S. mekongi DNA. While the consensus primer assays failed to detect $S$. mekongi DNA in human serum samples, the multi-primer assays showed positive or borderline positive results but only in $9.8 \%(6 / 61)$ of serum samples from patients with confirmed S. mekongi infections. Some cross-reactions with samples positive for S. mansoni or S. haematobium were observed but with the SjCHGCS19-PCR only. In spite of the low sensitivity, the presented experience may guide future evaluations of $S$. japonicum-complex-specific PCRs from human serum.

Keywords: Schistosoma mekongi; Schistosoma malayensis; hybridization probe; test evaluation; diagnosis; retrotransposon; multi-copy target; schistosomiasis; molecular diagnostics; test accuracy 


\section{Introduction}

Species of the Schistosoma japonicum complex with human pathogenic potential comprise S. mekongi and the closely related $S$. malayensis next to $S$. japonicum sensu stricto [1,2]. As a result of extensive ongoing Schistosoma-control and elimination programs in endemic settings [3,4], the quantitative disease burden due to $S$. japonicum complex is considerably lower compared to African schistosomiasis [5] caused by S. haematobium complex and S. mansoni complex [2], respectively, or compared to Latin American schistosomiasis caused by S. mansoni [5]. To eradicate residual parasite circulation, sensitive diagnostic tests are required [6].

For the African Schistosoma species, highly sensitive real-time PCRs targeting the multicopy sequences Sm1-7 for S. mansoni complex as well as Dra1 for S. haematobium complex in human serum have been developed [2,7-10] and well evaluated using sera from travel returnees [11,12] and individuals in endemic areas [13,14]. These assays provide highly sensitive tools for screening and facilitate the identification of both species complexes in parallel in human serum samples as a one-tube multiplex approach [12,14]. Currently, its potential usefulness for schistosomiasis surveillance and control activities is controversially discussed $[13,15,16]$. In contrast, its application for the diagnosis of early infections prior to seroconversion and prior to the excretion of eggs, as well as for the discrimination of active infections from old serological responses to infections that have been successfully cured long ago, is considered as well established [12-16].

For $S$. japonicum, the retrotransposon $S j R 2$ has been described at the start of the millennium as a highly repetitive genetic element, which might be a suitable PCR target for sensitive molecular diagnostic approaches [17]. In detail, as many as 10,000 SjR2 repeats per genome have been reported, representing about $14 \%$ of the $S$. japonicum genome [18]. In 2012, those estimations were corrected to a genome proportion of $4.43 \%$, corresponding to about 400 complete copies and 23,755 partial copies [19]. In the same study [19], the retrotransposon SjCHGCS19, which represents a genome proportion of $4.09 \%$ with 793 complete copies and 17,373 partial copies, was identified as another potential multi-copy PCR target. However, SjCHGCS19 is not specific for S. japonicum, as it is also present in S. mansoni [19].

Surprisingly, reports on the introduction, standardization and evaluation of diagnostic real-time PCR assays targeting repetitive genetic elements of S. japonicum complex in human serum are quite scarce. Focusing on the SjCHGCS19 target, nested PCR but not real-time PCR was described to identify S. japonicum DNA in serum samples [19]. Traditional gelbased PCRs, nested PCRs as well as SYBR Green-based but not probe-based real-time PCRs targeting $S j R 2$ have been used to identify S. japonicum in tissue and animal sera [20-26]. Other molecular diagnostic approaches targeting $S j R 2$ sequence fragments of $S$. japonicum include loop-mediated isothermal amplification (LAMP) [27,28], recombinase polymerase amplification [29], and droplet digital PCR [30], respectively.

To our knowledge, there is a lack of well-evaluated modern hybridization probe-based real-time PCR assays for the diagnosis of $S$. japonicum infections by targeting the highly repetitive genetic elements SjR2 or SjCHGCS19. Moreover, the described assays have not been adapted to cover S. mekongi and S. malayensis, two further Schistosoma spp. of the S. japonicum complex pathogenic to humans, because respective genomic information from these two species has not been available so far [31]. In this study, we aimed at establishing hybridization-probe real-time PCR assays targeting SjR2 and SjCHGCS19 for the diagnosis of infections with parasites of the $S$ japonicum complex in human serum samples.

\section{Materials and Methods}

\subsection{Samples}

A total of 61 residual volumes ( $200 \mu \mathrm{L}$ each) of serum samples from patients with microscopically proven S. mekongi infection were included as positive controls in the assessment. The residual serum samples had been stored frozen at $-80^{\circ} \mathrm{C}$ up to 10 years prior to the assessment and freeze-thawed several times. These serum samples had orig- 
inally been collected for serological testing from the local population $(n=60)[32,33]$ in the course of studies conducted in the endemic area in Lao People's Democratic Republic $(\mathrm{PDR})$ as well as from a Belgian traveler returning from Lao PDR $(\mathrm{n}=1)$ [34]. S. mekongi eggs were diagnosed, and the egg number per gram was counted by experienced microscopists in stool samples taken in parallel from all patients (mean: 51 eggs/gram, standard deviation: 144 eggs/gram, median: 18 eggs/gram, interquartile range IQR: (12, 30 eggs/gram), minimum-maximal (6, 1010 eggs/gram)). As detailed elsewhere [32-34], positive serological results had been observed in 40 out of 61 (65.6\%) patients. Concomitant helminth infections were proven by the detection of Opisthorchis viverrini eggs ( $\mathrm{n}=32$ stool samples), hookworm eggs ( $\mathrm{n}=23$ stool samples) and Trichuris trichiura eggs ( $\mathrm{n}=1$ stool sample), respectively.

Negative control samples comprised 50 residual serum samples from travel returnees with S. mansoni and/or S. haematobium infections as described in a previous study [12], which had also been stored at $-80^{\circ} \mathrm{C}$ for several years prior to the assessments. As detailed elsewhere [12], positive serum PCR for S. haematobium had been obtained in 21 instances (mean cycle threshold (Ct) value 33, standard deviation (SD) 5), positive serum PCR for S. mansoni in 33 instances (mean Ct 33, SD 4), with 8 mixed infections. Detection of antischistosomal antibodies had shown positive results in $27 / 50$ instances (54\%) next to another borderline positive result (2\%) [12]. S. mansoni eggs had been observed in stool samples in two of those 50 patients, S. haematobium eggs in urine of three patients as well as in sperm of an additional patient, respectively, without quantification attempts.

To ensure sufficient DNA quality of the historical serum samples, real-time PCR targeting the human $18 \mathrm{~S}$ rRNA gene, as described previously [35,36], had been sporadically performed with arbitrarily chosen study samples and fresh serum sample residuals from the diagnostic routine, showing no relevant $\mathrm{Ct}$ value shifts in the range of $24 \pm 2$.

Further, two urine samples with positive real-time PCR for S. haematobium (Ct 25 and $\mathrm{Ct} 30$, respectively) were included as additional negative controls. In the sample with $\mathrm{Ct} 25$, S. haematobium eggs had been microscopically detected as well.

In line with ethical requirements for this test evaluation study, no patient-specific data can be presented, which is an admitted violation of the STARD (Standards for Reporting Diagnostic Accuracy) criteria [37].

\subsection{Nucleic acid Extraction}

Nucleic acids had been extracted from the complete $200 \mu \mathrm{L}$ residual sample volumes using the QIAamp circulating nucleic acid kit (Qiagen, Hilden, Germany) according to the manufacturer's instructions [8].

\subsection{Real-Time PCRs}

The hybridization-probe-based real-time PCR assays targeting the retrotransposons SjR2 and SjCHGCS19 were designed according to the suggestions from the original publication by Driscoll and colleagues [17] as well as by Guo and colleagues [19]. As available sequence information, however, was restricted to S. japonicum sensu stricto (e.g., GenBank accession numbers AF412214.1, AY027869.1, FN293022.1, FN293026.1, FN293027.1 for SjR2 and FN356221.1 for SjCHGCS19, respectively), matching contigs from a short-read next generation sequencing (NGS) analysis of S. mekongi and S. malayensis cells taken from the reference material at the Bernhard Nocht Institute for Tropical Medicine Hamburg, which is the German National Reference Center for Tropical Pathogens, were also considered for the choice of the oligonucleotides. SjR2-like and SjCHGCS19-like sequences in S. mekongi and S. malayensis were identified with the software BLASTN 2.10.0+ as described recently [38]. The identified contigs are shown in Appendix A Table A1.

As the newly identified sequences were in part not optimally matched by the primer oligonucleotides suggested previously $[17,19]$, new real-time PCR oligonucleotides were designed with the aim of optimally covering all three pathogenic species within the $S$. japonicum complex and also to match the considerable sequence variability within the retrotrans- 
posons SjR2 and SjCHGCS19. For these purposes, both consensus PCRs and multi-primer PCRs to cover a broader range as sequence variants were designed in silico.

For initial test optimization, plasmids with a pEX-A128 backbone encircling the insert sequence were used. The SjR2-plasmid insert comprised the new sequence from the Appendix A Table A1, while the GenBank accession number FN356221.1 sequence was used for the SjCHGCS19-plasmid. After optimization, both the consensus and the multiprimer PCRs showed a limit of detection within the $10^{3}$ copies per $\mu \mathrm{L}$ eluate range for the SjR2 target and within the $10^{2}$ copies per $\mu \mathrm{L}$ eluate range for the SjCHGCS19 target when performed with the plasmids. Only after those pre-assessments, the protocols were compared with DNA from S. mekongi worms grown in the culture at the Mahidol University in Bangkok, Thailand (see results).

The master mix of all real-time PCRs comprised HotStar Taq Mastermix (Qiagen, Hilden, Germany) with a total $\mathrm{Mg}^{2+}$ concentration of $6.0 \mathrm{mM}, 0.5 \mathrm{pmol} / \mu \mathrm{L}$ of each primer, $0.3 \mathrm{pmol} / \mu \mathrm{L}$ of the probe, $0.005 \mathrm{mg} / \mathrm{mL}$ bovine serum albumin, and $5.0 \mu \mathrm{L}$ DNA eluate in total volumes of $20 \mu \mathrm{L}$, respectively. The run protocols were as follows: Heating to $95^{\circ} \mathrm{C}$ for 15 minutes followed by 50 cycles of denaturation at $95^{\circ} \mathrm{C}$ for $15 \mathrm{~s}$, annealing for $60 \mathrm{~s}$ at $60^{\circ} \mathrm{C}$ and amplification at $72{ }^{\circ} \mathrm{C}$ for $60 \mathrm{~s}$ each, followed by cooling to $40{ }^{\circ} \mathrm{C}$ for $20 \mathrm{~s}$. The PCRs were run on magnetic induction cyclers (MIC; Bio Molecular Systems Ltd., London, UK). Inhibition of the PCR reactions was excluded with a protocol based on the amplification of Phocid herpes virus DNA as described previously [39]. All PCRs were run with a plasmid-based positive control and a PCR-grade water-based negative control.

Positive PCR results were defined by cycle threshold $(\mathrm{Ct})$ values $\leq 35$ and exponential amplification. In the case of $\mathrm{Ct}$ values $>35$ and/or atypical shapes of the amplification curves, the results were considered borderline positive.

\subsection{Statistics}

Due to the low number of available samples for the evaluation, the results were descriptively presented only.

\subsection{Ethics}

Ethical clearance for the anonymous use of residual sample materials for the test assessments was provided by the medical association of Hamburg, Germany (reference number: WF-011/19) on 11th March 2019 without a need for informed consent. The evaluation study was performed in line with the guidelines of the Declaration of Helsinki.

\section{Results}

\subsection{Adaptation of the Oligonucleotide Compositions to Increase the Sensitivity of S. japonicum Complex PCR}

Due to the lack of sequence information in public databases corresponding to $S$. japonicum retrotransposons SjR2 [17] and SjCHGCS19 [19] in S. mekongi and S. malayenis, the genomes of the latter two species were partially sequenced (see methods). This revealed additional sequence information to design new consensus primers and probes covering all three species of the $S$. japonicum complex. In addition, as there is considerable sequence variability of the different retrotransposon copies even within the same species, various primer combinations were introduced into multi-primer PCR assays in order to increase sensitivity when applied to DNA extracted from helminth material instead of plasmids which are usually used as positive controls.

Compared to consensus real-time PCR with helminth DNA of S. mekongi, sensitivity could be increased by 0.5 and 6.6 cycles for SjR2 and SjCHGCS19 sequences, respectively, using the multi-primer PCRs (consensus primer cycle threshold ( $\mathrm{Ct}$ ) values versus (vs.) multi primer Ct values 9.2 vs. 8.7 for $S j R 2$ and 14.0 vs. 7.4 for SjCHGCS19). Adding this additional sensitivity increase to the limits of detection as obtained with the positive control plasmids (see methods), copy numbers of the targeted retrotransposons as they can be expected within a single helminth cell were within the sensitivity range. The multi-primer 
PCRs were, accordingly, included in the application with residual serum samples from patients with S. mekongi infections. The oligonucleotide sequences of the various PCR primers and probes are shown in Table 1.

\subsection{PCR Reactions with Residual Serum Samples from Patients with S. mekongi Infections}

Positive or borderline positive real-time PCR signals were achieved in 6 out of 61 $(9.8 \%)$ residual serum samples from patients with S. mekongi infections, as collected in the course of recent studies [32-34] using multi-primer PCRs, while no signals were obtained with consensus primer PCRs. In detail, an unambiguously positive result (serum Ct 35) was obtained with the multi-primer SjR2 real-time PCR in a patient with 228 S. mekongi eggs per gram stool, another borderline result (serum Ct 38) in a patient with 60 eggs/gram. With the SjCHGCS19 multi-primer real-time PCR, 4 borderline positive signals with Ct values of $37,38,44$ and 45 , respectively, were recorded in serum samples from patients with 1110, 24, 36 , and 132 S. mekongi eggs per gram stool, respectively. There was no matching regarding the positive signals obtained with both multi-copy PCR assays. Patients with positive or borderline positive signals in S. japonicum complex-specific real-time PCR showed egg counts per gram stool higher than the median value of 18 eggs/gram in all instances and higher than the mean value of 51 eggs/gram in 4 out of 6 instances, respectively.

3.3. PCR Reactions with Negative Control Residual Serum Samples from Patients with S. mansoni or S. haematobium Infections

In 50 residual sera from patients with S. haematobium or S. mansoni infection [12], the SjR2 multi-primer real-time PCR did not show any cross-reaction. The SjCHGCS19 multiprimer real-time PCR showed two positive results (Ct values 31 and 35, respectively) in the serum of two patients with double infections due to S. haematobium (serum Ct values 32 and 20 in S. haematobium-specific Dra1 real-time PCR, respectively) and S. mansoni (serum Ct values 39 and 23 in S. mansoni-specific Sm1-7 real-time PCR, respectively), as well as one borderline positive result (serum $\mathrm{Ct}$ value 36 ) in a patient with $\mathrm{S}$. mansoni (serum $\mathrm{Ct}$ value 33 in S. mansoni-specific Sm1-7-PCR). As shown for these three samples, differences between the Ct values of S. mansoni complex-specific Sm1-7 real-time PCR, S. haematobium complexspecific Dra1 real-time PCR and S. japonicum complex-specific multi-primer SjCHGCS19 real-time PCR were highly variable ranging from +1 to -12 . Additionally, there was no obvious hint for a preferential cross-reaction of SjCHGCS19 real-time PCR in samples with particularly low $\mathrm{Sm} 1-7$ and Dral Ct values, as cross-reactions were also recorded in samples close to the $\mathrm{Ct}$ mean values of the negative control sample collection as observed with $S$. haematobium complex-specific and S. mansoni complex-specific PCR.

In the two assessed urine samples positive for S. haematobium in Dra1 PCR, the sample with the Dra1 Ct value of 25 and microscopically visible $S$. haematobium eggs showed a positive SjCHGCS19 multi-primer real-time PCR result (Ct value 34), while the other urine sample with a Dra1 Ct value of 30 went undetected in the SjCHGCS19 assay. 
Table 1. Oligonucleotides applied in the consensus PCRs and multi-primer PCRs targeting the SjR2 sequence and the SjCHGCS19 sequence of S. japonicum complex DNA.

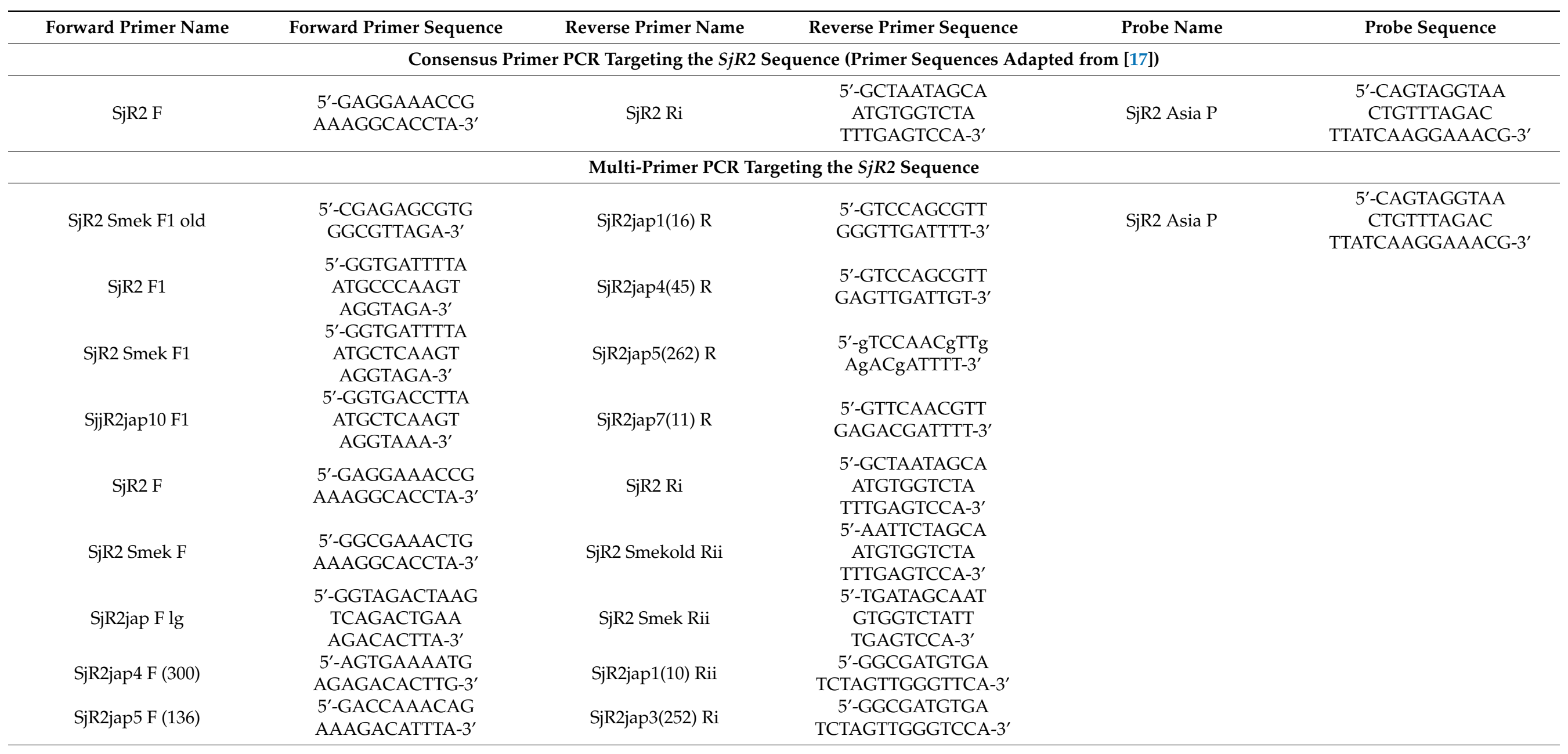


Table 1. Cont.

\begin{tabular}{|c|c|c|c|c|c|}
\hline Forward Primer Name & Forward Primer Sequence & Reverse Primer Name & Reverse Primer Sequence & Probe Name & Probe Sequence \\
\hline \multicolumn{6}{|c|}{ Consensus Primer PCR Targeting the SjCHGCS19 Sequence (Primer Sequences Unchanged from [19]) } \\
\hline Guo-SjCHGCS19 F & $\begin{array}{c}\text { 5'-CCAAATCGCA } \\
\text { ACACTACG-3' }\end{array}$ & Guo-SjCHGCS19 R & $\begin{array}{l}\text { 5'-ATCGGATTCT } \\
\text { CCTTGTTCAT-3' }\end{array}$ & Guo2012 P & $\begin{array}{l}\text { 5'-AATGGAACTC } \\
\text { GTCAYTGTAC } \\
\text { ATCAACTTCA-3' }\end{array}$ \\
\hline \multicolumn{6}{|c|}{ Multi-Primer PCR Targeting the SjCHGCS19 Sequence } \\
\hline $7436 \mathrm{~F}$ & $\begin{array}{l}\text { 5'-ACCCACCAGW } \\
\text { CATCGAAGCA-3' }\end{array}$ & $9292 \mathrm{~A}$ & $\begin{array}{l}\text { 5'-RGCCTGTTGA } \\
\text { TCTCGAAGTTG-3' }\end{array}$ & $9015 \mathrm{P}$ & $\begin{array}{c}\text { 5'-ACCAGGRAAA } \\
\text { GTCTTCAACAGAGTGTT- } \\
3^{\prime}\end{array}$ \\
\hline $7443 \mathrm{~F}$ & $\begin{array}{l}\text { 5'-CCACCAGWCA } \\
\text { TCGAAGCAGC-3' }\end{array}$ & $9292 \mathrm{R}$ & $\begin{array}{l}\text { 5'-RGCCTGTTGA } \\
\text { TCTCGAAGTT-3' }\end{array}$ & $3483 \mathrm{P}$ & $\begin{array}{c}\text { 5'-CACCAACGAT } \\
\text { GRAAGAAATC } \\
\text { AAGATRGYY-3' }\end{array}$ \\
\hline $2980 \mathrm{~F}$ & $\begin{array}{l}\text { 5'-RARAAAGCTG } \\
\text { CAAGAGAAGG-3' }\end{array}$ & $3604 \mathrm{R}$ & $\begin{array}{l}\text { 5'-TCCTGCTGCT } \\
\text { TTCCCACTTT-3' }\end{array}$ & & \\
\hline $2983 \mathrm{~F}$ & $\begin{array}{l}\text { 5'-RAAAGCTGCA } \\
\text { AGAGAAGGAA-3' }\end{array}$ & $3613 \mathrm{R}$ & $\begin{array}{l}5^{\prime} \text {-TGTCAGGTCC } \\
\text { TGCTGCTTTC-3' }\end{array}$ & & \\
\hline $3956 \mathrm{~F}$ & $\begin{array}{l}\text { 5'-ACAGAGGRAT } \\
\text { CACACTRTTG } \\
\text { TCAGT-3' }\end{array}$ & $3615 \mathrm{R}$ & $\begin{array}{l}\text { 5'-TTGTCAGGTC } \\
\text { CTGCTGCTTT-3' }\end{array}$ & & \\
\hline 3956Sma F & $\begin{array}{c}\text { 5'-ATAGGGGGAT } \\
\text { CACACTACTG } \\
\text { TCAGT-3' }\end{array}$ & $4113 \mathrm{R}$ & $\begin{array}{l}\text { 5'-RAAGTTGAGC } \\
\text { ATCCACTGAR-3' }\end{array}$ & & \\
\hline 3956Sme3 F & $\begin{array}{l}\text { 5'-AAAGAGAGAT } \\
\text { CACGCTACTG } \\
\text { TCGAT-3' }\end{array}$ & 4113Sma R & $\begin{array}{l}\text { 5'-AAAGTTAAGT } \\
\text { ACCACTGAA-3' }\end{array}$ & & \\
\hline 3956Sme3 F I & $\begin{array}{c}\text { 5'-ACATAGAGAT } \\
\text { CACACTACTG } \\
\text { TCGGT-3' }\end{array}$ & & & & \\
\hline
\end{tabular}




\section{Discussion}

Hybridization-probe-based real-time PCR targeting multi-copy sequences is a wellestablished approach for the diagnosis of infections with parasites of the S. haematobium complex and the S. mansoni complex in human serum [2,7-14]. To facilitate the diagnosis of schistosomiasis caused by parasites of the Asian S. japonicum complex, calls for action to develop similar diagnostic options were published earlier [34]. The retrotransposons SjR2 and SjCHGCS19 were identified as potential targets $[17,19]$ due to their high numbers of repeats within the genomes of members of the S. japonicum complex [19]. In line with this, these sequences have been repeatedly used for the diagnostic detection of S. japonicum [19-30]. However, hybridization-probe-based real-time PCR assays with human serum targeting not only S. japonicum but also S. mekongi and S. malayensis have not yet been broadly evaluated so far.

In the study presented here, we provided the proof of principle that SjR2- and SjCHGSC19-based real-time PCR can be used to diagnose S. mekongi infections in human serum. Sensitivity was, however, poor with positive or borderline positive PCR signals in less than $10 \%$ of the assessed historical serum samples from patients with microscopically proven S. mekongi infections. However, even this low sensitivity was only reached by combinations of primers targeting different variants of the retrotransposons. Further, parallel microscopic stool assessments from the study participants suggested that positive serum PCR signals were predominantly observed in patients with more severe infections, as demonstrated by higher loads of $S$. mekongi eggs per stool volume. Even in those more severely infected individuals, however, the positive results of SjR2- and SjCHGCS19specific PCRs did not match directly, suggesting target DNA concentrations close to the limit of detection. More than this, even the sensitivity of the multi-primer PCR assays as described here could be achieved by several adaptations of the oligonucleotides only.

While SjR2-specific PCR did not show any cross-reaction with serum and urine samples positive for the African Schistosoma species S. haematobium and S. mansoni, such cross-reaction was inconsistently observed for the SjCHGCS19-specific multi-primer PCR. Considering the low sensitivity of SjR2-PCR even in serum of S. mekongi patients, however, this seemingly better specificity is difficult to interpret. Nevertheless, the recorded cross-reactions of the SjCHGCS19-PCR are not surprising as well, as positive results of SjCHGCS19-specific PCRs in samples from patients with S. mansoni infections were already reported by Guo and colleagues [19]. Insofar, the results of the specificity testing with serum samples from patients with infections due to phylogenetically related Schistosoma spp. such as $S$. mansoni had been expected. Here, we were able to show that $S$. haematobium is detected by SjCHGCS19-PCR as well. Interestingly, only a few samples showed such cross-reactivity, and there was no obvious association with parasite DNA loads, as suggested by Sm1-7-PCR and Dra1-PCR with specificity for S. mansoni complex and S. haematobium complex, respectively. In contrast, the observed differences between $\mathrm{Ct}$ values of SjCHGCS19-PCR and Sm1-7-PCR or Dra1-PCR were highly variable among the few samples with overlapping positive results. This observation suggests high sequence variability of the SjCHGCS19 sequences within non-S. japonicum complex schistosomes, explaining the apparent inconsistency of positive SjCHGCS19-PCR results.

The reasons for the much lower diagnostic sensitivity of SjR2-PCR and SjCHGCS19PCR for the detection of $S$. japonicum complex PCR in human serum compared to PCRs for other highly repetitive multi-copy targets like S. mansoni complex-specific Sm1-7-PCR or S. haematobium complex-specific Dra1-PCR [2,7-14] remain speculative. High genetic intra-species variability of the retrotransposons and varying numbers of repeats within individual worms as described elsewhere $[18,19]$ might make SjR2 and SjCHGCS19 sequences less suitable as real-time PCR targets, at least for the diagnosis from human serum.

For the diagnosis from other sample materials such as stool, however, less complex target sequences like ribosomal gene sequences of S. japonicum, for which hybridization probe-based real-time PCR has already been introduced [40], may be sufficient. The multiprimer PCRs for SjR2 and SjCHGCS19, in contrast, should not be applied in complex 
samples like stool specimens from patients with a high likelihood of various helminth infections prior to thorough evaluations of these assays with stool samples obtained from such settings. The latter would have been beyond the scope of the present work, and we also did not have suitable samples for this; however, specificity issues of multi-primer PCRs applied with stool samples are known from other previous assessments performed with group-specific helminth PCRs [41].

In human blood, in contrast, highly repetitive multi-copy targets seem to show superior sensitivity, as recently demonstrated in a comparison of ITS-2-based real-time PCR and Sm1-7-based real-time PCR for the diagnosis of $S$. mansoni-specific DNA in human EDTA blood samples [12]. Another hypothetical reason for the poor scoring of the S. japonicum complex-specific multi-primer PCRs might be reduced circulation of free helminth DNA in the peripheral blood in case of $S$. japonicum complex infections compared to infections with S. mansoni or S. haematobium. The design of this study, unfortunately, did not allow to answer this question.

It remains speculative whether or not DNA extraction from high serum volumes up to $20 \mathrm{~mL}$ as earlier suggested for S. mansoni-specific Sm1-7-serum-PCR [7] might have increased the diagnostic sensitivity of SjR2-PCR and SjCHGCS19-PCR. Respective high residual sample volumes, however, were not available for the evaluations presented here.

Altogether, the limited availability of serum samples from patients with confirmed S. japonicum complex infections both in numbers and regarding their residual volumes was the main limitation of the study. This restriction also prevented the assessment of different nucleic acid extraction strategies, which may hypothetically have led to improved sensitivity. Additionally, the low volumes made repetitive testing impossible because the eluates were rapidly gone after just a few PCR runs. Another limitation was the need for relying on historical serum reference sample materials due to the scarce availability of fresh samples from patients with $S$. japonicum complex infections. Although real-time PCR targeting the human 18S rRNA gene [35,36], which was performed from randomly chosen samples to estimate the DNA quality (see methods), did not suggest considerable degradation of human DNA within the samples, it can only be speculated whether this also applied to free helminth DNA. As the $S$. mekongi serum samples had originally been collected for serological test purposes and not for DNA detection, they had been treated accordingly in the diagnostic process and stored at $-80{ }^{\circ} \mathrm{C}$ with several freeze-thaw cycles. Further, it remains uncertain if the late stage of infection, as indicated by the shed eggs of the patients, might also have contributed to the observed low sensitivity. As known from the Sm1-7-specific real-time PCR, the amount of Schistosoma spp.-DNA in serum varies depending on the stage of infection [34]. Finally, due to the lack of suitable specimens, only serum samples from patients with $S$. mekongi were assessed. Accordingly, the evaluation presented here does not comprise all species of the $S$. japonicum complex. However, due to the high genetic similarity of the target sequences in the different species as suggested by the obtained next generation sequencing results (see Methods and Appendix A), it is likely that the PCR results will be similar using serum samples from patients infected with S. japonicum or S. malayensis.

Although mainly negative results are presented, the experiences described in this study may guide the future development of $S$. japonicum complex-specific PCRs from human serum.

\section{Conclusions}

The assessment allowed the proof of principle for the use of hybridization probebased real-time PCR for the detection of S. japonicum complex in human serum samples by targeting retrotransposon sequences. Low positivity rates in residual materials of clinical samples, however, leave room for further improvement and calls for evaluations with fresh sample materials. The experience from this work may help to guide future test development and evaluation approaches in areas of endemicity. 
Author Contributions: Conceptualization, H.F., U.L. and E.T.; methodology, H.F., G.L., O.L. and T.T.; software, T.T. and G.L.; validation, H.F.; formal analysis, H.F. and T.T.; investigation, H.F.; resources, B.N., S.P., M.V.E., I.M., L.C., P.A., P.O., S.S. and E.T.; data curation, H.F. and T.T.; writing-original draft preparation, H.F.; writing-review and editing, H.F., U.L., B.N., S.P., P.O., S.S., M.V.E., I.M., L.C., P.A., G.L., O.L., T.T. and E.T.; supervision, H.F. and E.T.; project administration, H.F.; funding acquisition, H.F. and E.T. All authors have read and agreed to the published version of the manuscript.

Funding: The experiments were funded by grant 36K2-S-45 1922 on the "Evaluation and optimization of molecular diagnostic tests for tropical parasitic diseases for surveillance and risk assessment purposes in tropical deployment settings-a German-French cooperation project between the German Armed Forces Hospital Hamburg and the Military Hospital Laveran, Marseille" of the German Ministry of Defense (MoD) awarded to Hagen Frickmann. We acknowledge support from the Open Access Publication Funds of the Bernhard Nocht Institute for Tropical Medicine Hamburg. The publication of this article was funded by the Open Access Fund of the Leibniz Association. The sponsors did not have any role in the collection, analysis or interpretation of data, the writing of the report or in the decision to submit the article for publication.

Institutional Review Board Statement: Ethical clearance for the anonymous use of residual sample materials for the test assessments was provided by the medical association of Hamburg, Germany (reference number: WF-011/19) on 11th March 2019 without a need for informed consent. The evaluation study was performed in line with the guidelines of the Declaration of Helsinki.

Informed Consent Statement: Not applicable.

Data Availability Statement: All relevant data are provided in the manuscript. Raw data can be made available on reasonable demand.

Acknowledgments: The authors would like to thank Takeshi Agatsuma, Kochi University, Japan, for providing several specimens of Schistosoma malayensis and Simone Priesnitz, Annett Michal, Stefanie Ruben and Birgit Muntau for excellent technical assistance.

Conflicts of Interest: Gérard Leboulle and Olfert Landt are representatives of TIB MOLBIOL, Berlin, Germany. The funders had no role in the design of the study; in the collection, analyses or interpretation of data; in the writing of the manuscript; or in the decision to publish the results. 


\section{Appendix A}

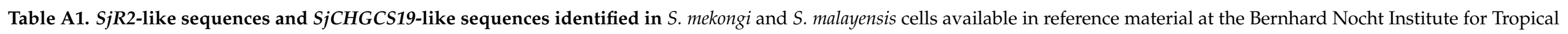
Medicine, Hamburg, Germany.

Contig of a Sjr2-Like Sequence as Identified in both S. mekongi and S. malayensis

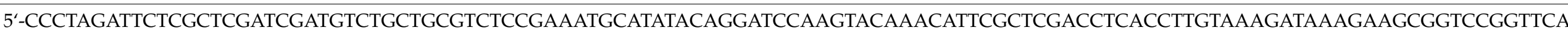
CCCTTCGTGTTTCCGGAGACGCCATCGCTACCACTCGAGGCCTTGCTAGTGTAGGCATAGCACTAAATTCAAAAGCTGAACAGGCTCTCCTTCACTGGATTCCCATAGATAGT CGCTTATGCGCTGTCCGTCTAAACGGGAGGGTAAGAACTCGTAAAGATAGGGACACACGCCGTTGCGTTTTAGTTATGTCTGCCTAAGCTCCCAGTGATTGAAGCTCTGATG AAGTAAAAGATTAATTTTACAGAAAGCTTTCCGACCTCCTTCGGAAAGCTAAGAGTACTGATGTAGTGATCGTGGCTGGTGATTTTAATGCTCAAGTAGGTAGATTAGGCGAA

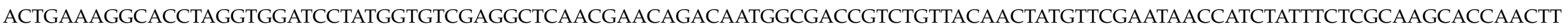

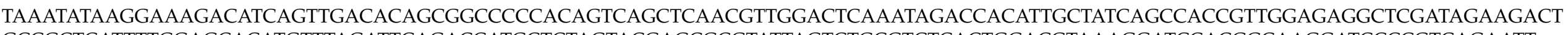

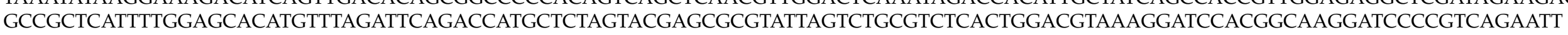

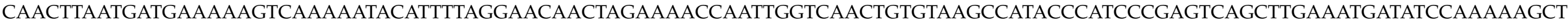

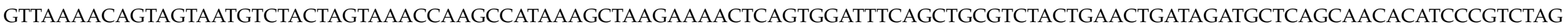

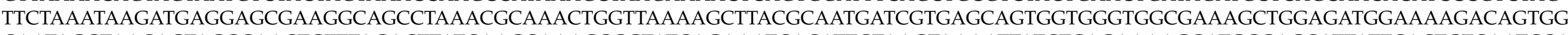

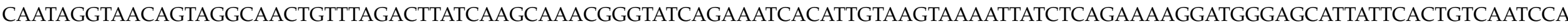

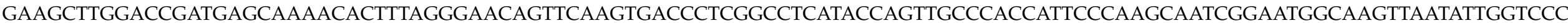
CCAAGTCTTAGTGAGGTTGAGAAGACTATAGGAAATCAAAAGCGAGGGAGAGCAGCAAGACCTGATGGATTAACCCTTGAGATATTTAAGGATGGTAGT-3،

Contig of a SjCHGCS19-Like Sequence as Identified in S. mekongi Variant 1

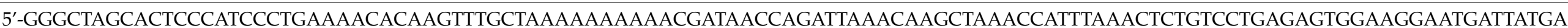

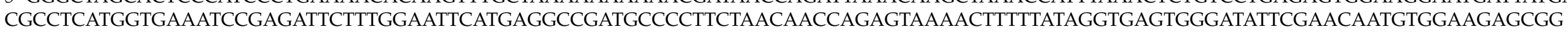

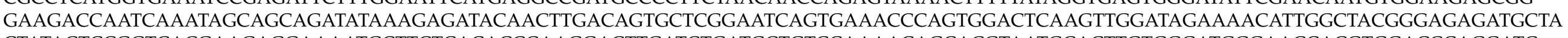

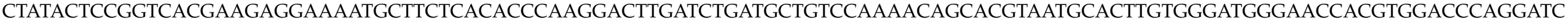

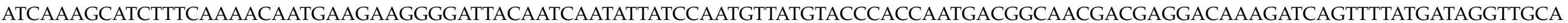

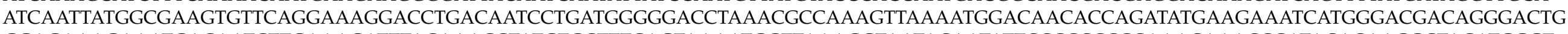

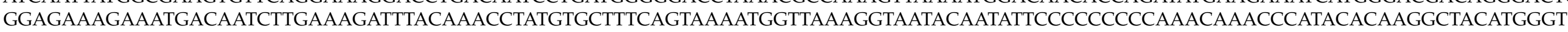

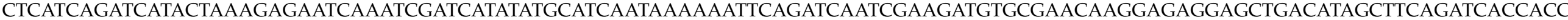

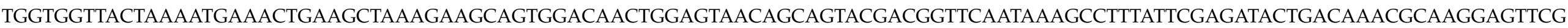

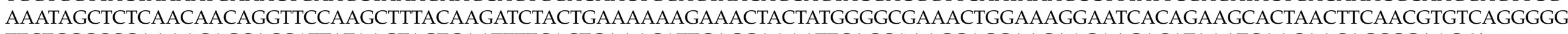
TTCTGGGCCGAAAACAGCACCATTATAAGTAGTGAATTTTCACTGAAACATTGAGGAAAATTCAGCAAAGGAGGAACAAGAAGACATAAATCAACAACAGCGGAAC-3' 
Table A1. Cont.

Contig of a SjCHGCS19-Like Sequence as Identified in S. mekongi Variant 2

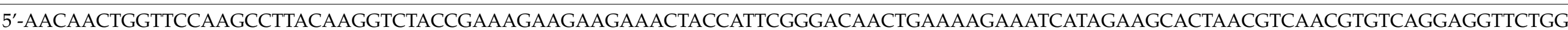

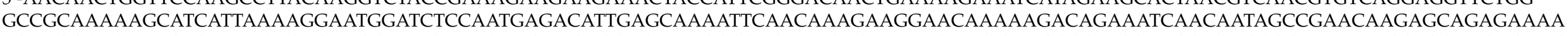

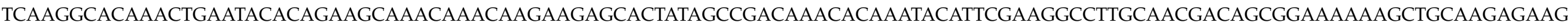

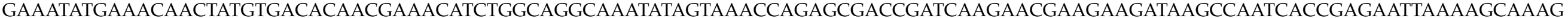

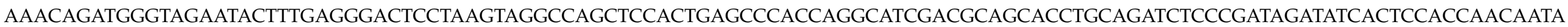

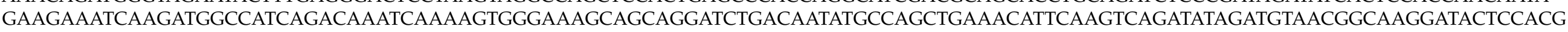

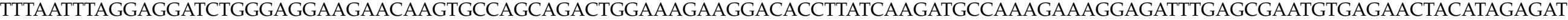

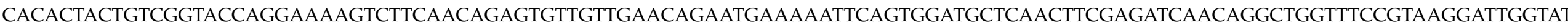

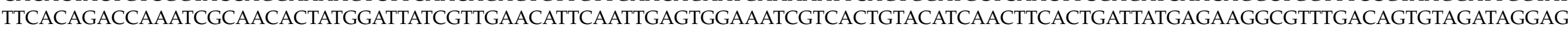

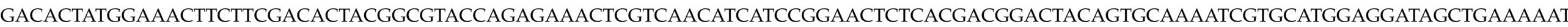
GCATTCCCAATGAAGACCGGAGTCAGACAAGGTTGTCTACTCTCGCCATTCCTCTTTCTTCTAGTAGTTAACTGGATCATGGAGACCTTCACATCTGAG-3'

\section{Contig of a SjCHGCS19-Like Sequence as Identified in S. mekongi Variant 3}

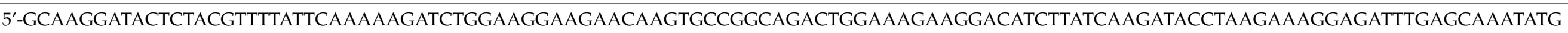

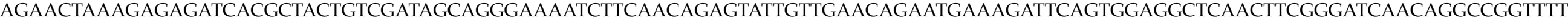

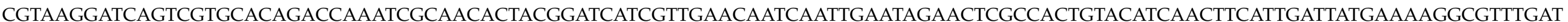

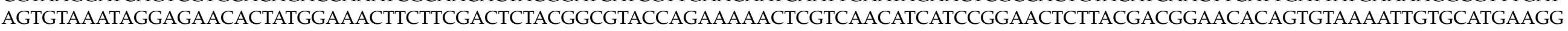

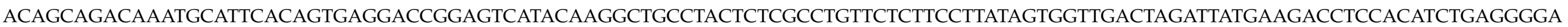

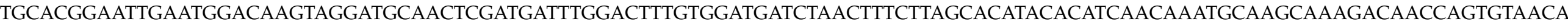

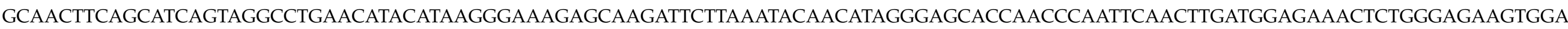

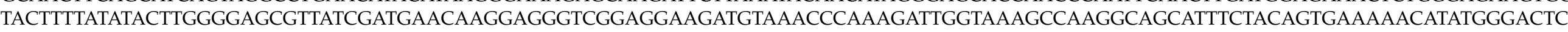

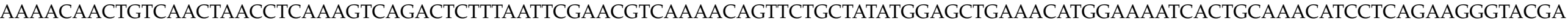

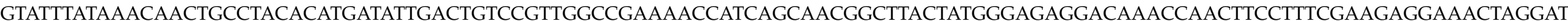

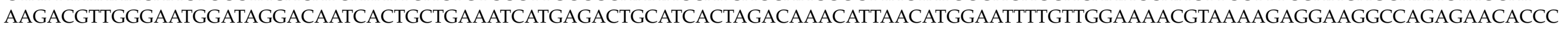
GGTGTGGAGATTGGAAACAGAAATTTAAAAAGAAAAAAGGAACCGGAAAAACCTGGAACGGATGGCCCAGGGAGAGTTTAA-3' 
Table A1. Cont.

Contig of a SjCHGCS19-Like Sequence as Identified in S. malayensis

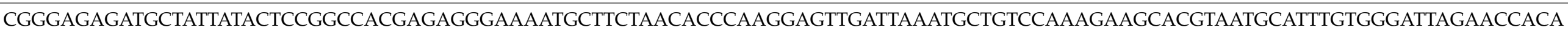

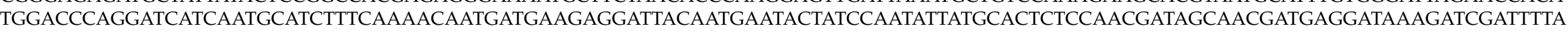

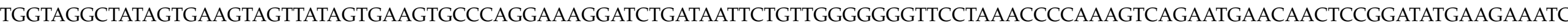

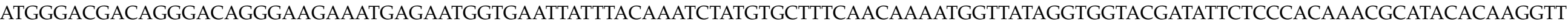

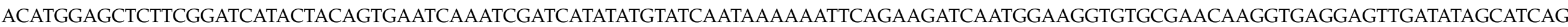

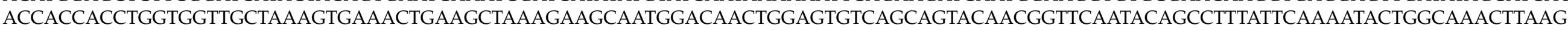

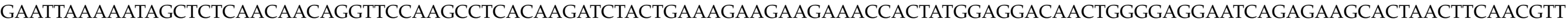

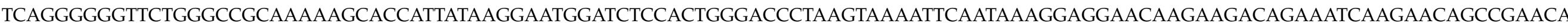

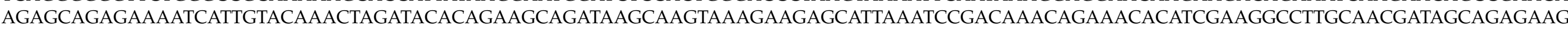

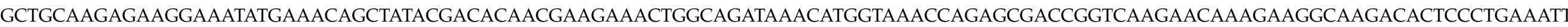

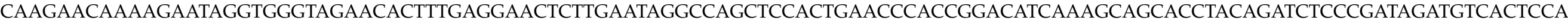

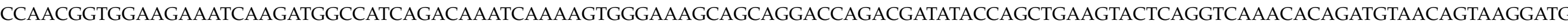

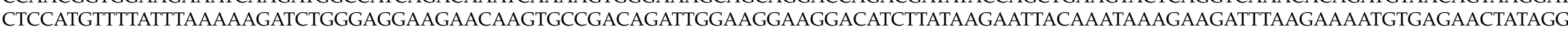

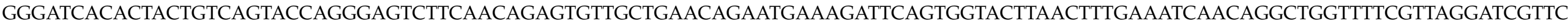

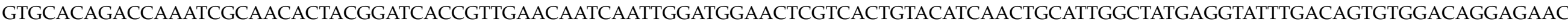

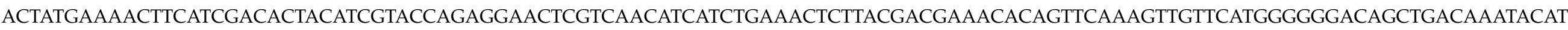

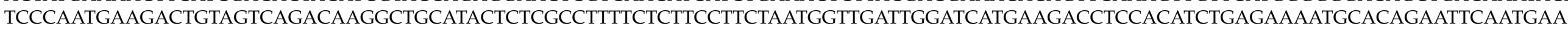

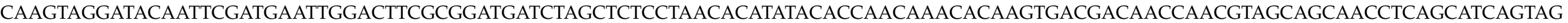

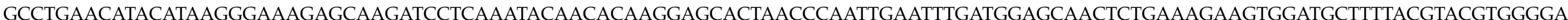

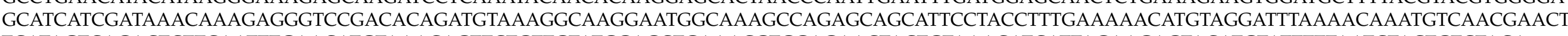

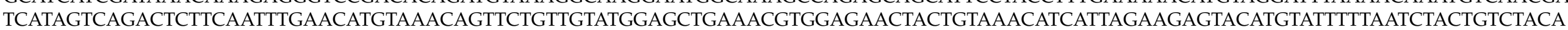

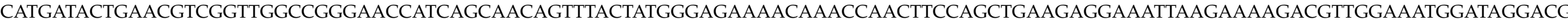

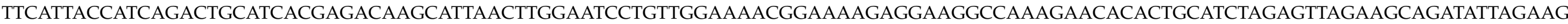

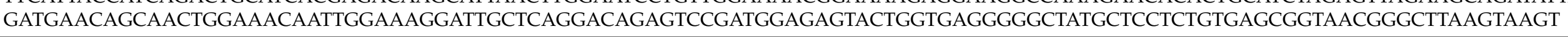




\section{References}

1. Greer, G.J.; Ow-Yang, C.K.; Yong, H.S. Schistosoma malayensis n. sp.: A Schistosoma japonicum-complex schistosome from Peninsular Malaysia. J. Parasitol. 1988, 74, 471-480. [CrossRef] [PubMed]

2. Cnops, L.; Soentjens, P.; Clerinx, J.; Van Esbroeck, M. A Schistosoma haematobium-specific real-time PCR for diagnosis of urogenital schistosomiasis in serum samples of international travelers and migrants. PLoS Negl. Trop. Dis. 2013, 7, e2413. [CrossRef]

3. Cao, C.L.; Zhang, L.J.; Deng, W.P.; Li, Y.L.; Lv, C.; Dai, S.M.; Feng, T.; Qin, Z.Q.; Duan, L.P.; Zhang, H.B.; et al. Contributions and achievements on schistosomiasis control and elimination in China by NIPD-CTDR. Adv. Parasitol. 2020, 110, 1-62. [PubMed]

4. Gordon, C.A.; Kurscheid, J.; Williams, G.M.; Clements, A.C.A.; Li, Y.; Zhou, X.N.; Utzinger, J.; McManus, D.P.; Gray, D.J. Asian Schistosomiasis: Current Status and Prospects for Control Leading to Elimination. Trop. Med. Infect. Dis. 2019, 4, 40. [CrossRef] [PubMed]

5. Aula, O.P.; McManus, D.P.; Jones, M.K.; Gordon, C.A. Schistosomiasis with focus on Africa. Trop. Med. Infect. Dis. 2021, 6, 109. [CrossRef]

6. Amoah, A.S.; Hoekstra, P.T.; Casacuberta-Partal, M.; Coffeng, L.E.; Corstjens, P.L.A.M.; Greco, B.; van Lieshout, L.; Lim, M.D.; Markwalter, C.F.; Odiere, M.R.; et al. Sensitive diagnostic tools and targeted drug administration strategies are needed to eliminate schistosomiasis. Lancet Infect. Dis. 2020, 20, e165-e172. [CrossRef]

7. Wichmann, D.; Panning, M.; Quack, T.; Kramme, S.; Burchard, G.D.; Grevelding, C.; Drosten, C. Diagnosing schistosomiasis by detection of cell-free parasite DNA in human plasma. PLoS Negl. Trop. Dis. 2009, 3, e422. [CrossRef] [PubMed]

8. Wichmann, D.; Poppert, S.; Von Thien, H.; Clerinx, J.; Dieckmann, S.; Jensenius, M.; Parola, P.; Richter, J.; Schunk, M.; Stich, A.; et al. Prospective European-wide multicentre study on a blood based real-time PCR for the diagnosis of acute schistosomiasis. BMC Infect. Dis. 2013, 13, 55. [CrossRef] [PubMed]

9. Hamburger, J.; Abbasi, I.; Ramzy, R.M.; Jourdane, J.; Ruppel, A. Polymerase chain reaction assay based on a highly repeated sequence of Schistosoma haematobium: A potential tool for monitoring schistosome-infested water. Am. J. Trop. Med. Hyg. 2001, 65, 907-911. [CrossRef]

10. Abbasi, I.; Webster, B.L.; King, C.H.; Rollinson, D.; Hamburger, J. The substructure of three repetitive DNA regions of Schistosoma haematobium group species as a potential marker for species recognition and interbreeding detection. Parasit. Vectors $\mathbf{2 0 1 7 , 1 0 , 3 6 4 . ~}$ [CrossRef]

11. Guegan, H.; Fillaux, J.; Charpentier, E.; Robert-Gangneux, F.; Chauvin, P.; Guemas, E.; Boissier, J.; Valentin, A.; Cassaing, S.; Gangneux, J.P.; et al. Real-time PCR for diagnosis of imported schistosomiasis. PLoS Negl. Trop. Dis. 2019, 13, e0007711. [CrossRef] [PubMed]

12. Frickmann, H.; Lunardon, L.M.; Hahn, A.; Loderstädt, U.; Lindner, A.K.; Becker, S.L.; Mockenhaupt, F.P.; Weber, C.; Tannich, E. Evaluation of a duplex real-time PCR in human serum for simultaneous detection and differentiation of Schistosoma mansoni and Schistosoma haematobium infections-Cross-sectional study. Travel Med. Infect. Dis. 2021. Epub ahead of print. [CrossRef] [PubMed]

13. Fuss, A.; Mazigo, H.D.; Mueller, A. Evaluation of serum-based real-time PCR to detect Schistosoma mansoni infection before and after treatment. Infect. Dis. Poverty 2020, 9, 74. [CrossRef] [PubMed]

14. Hoffmann, T.; Carsjens, I.; Rakotozandrindrainy, R.; Girmann, M.; Randriamampionona, N.; Maïga-Ascofaré, O.; Podbielski, A.; Hahn, A.; Frickmann, H.; Schwarz, N.G. Serology- and Blood-PCR-Based Screening for Schistosomiasis in Pregnant Women in Madagascar-A Cross-Sectional Study and Test Comparison Approach. Pathogens 2021, 10, 722. [CrossRef] [PubMed]

15. Hoekstra, P.T.; van Esbroeck, M.; de Dood, C.J.; Corstjens, P.L.; Cnops, L.; van Zeijl-van der Ham, C.J.; Wammes, L.J.; van Dam, G.J.; Clerinx, J.; van Lieshout, L. Early diagnosis and follow-up of acute schistosomiasis in a cluster of infected Belgian travellers by detection of antibodies and circulating anodic antigen (CAA): A diagnostic evaluation study. Travel Med. Infect. Dis. 2021, 41, 102053. [CrossRef] [PubMed]

16. Cnops, L.; Huyse, T.; Maniewski, U.; Soentjens, P.; Bottieau, E.; Van Esbroeck, M.; Clerinx, J. Acute Schistosomiasis with a Schistosoma mattheei $\times$ Schistosoma haematobium Hybrid Species in a Cluster of 34 Travelers Infected in South Africa. Clin. Infect. Dis. 2021, 72, 1693-1698. [CrossRef]

17. Driscoll, A.J.; Kyle, J.L.; Remais, J. Development of a novel PCR assay capable of detecting a single Schistosoma japonicum cercaria recovered from Oncomelania hupensis. Parasitology 2005, 131, 497-500. [CrossRef]

18. Laha, T.; Brindley, P.J.; Smout, M.J.; Verity, C.K.; McManus, D.P.; Loukas, A. Reverse transcriptase activity and untranslated region sharing of a new RTE-like, non-long terminal repeat retrotransposon from the human blood fluke, Schistosoma japonicum. Int. J. Parasitol. 2002, 32, 1163-1174. [CrossRef]

19. Guo, J.J.; Zheng, H.J.; Xu, J.; Zhu, X.Q.; Wang, S.Y.; Xia, C.M. Sensitive and specific target sequences selected from retrotransposons of Schistosoma japonicum for the diagnosis of schistosomiasis. PLoS Negl. Trop. Dis. 2012, 6, e1579. [CrossRef]

20. Gu, K.; Li, Y.; Driguez, P.; Zeng, Q.; Yu, X.; Sun, H.; Cai, L.; He, Y.; Wang, W.; McManus, D.P. Clinical diagnostic value of viable Schistosoma japonicum eggs detected in host tissues. BMC Infect. Dis. 2017, 17, 244. [CrossRef] [PubMed]

21. Zhao, X.; Gu, K.; Zeng, Q.; Gao, L.; Cheng, D. Diagnostic Value of SjR2 Gene in Colonic Tissue from Schistosoma Japonicum Infected Hosts. Med. Sci. Monit. 2019, 25, 427-435. [CrossRef]

22. Xia, C.M.; Rong, R.; Lu, Z.X.; Shi, C.J.; Xu, J.; Zhang, H.Q.; Gong, W.; Luo, W. Schistosoma japonicum: A PCR assay for the early detection and evaluation of treatment in a rabbit model. Exp. Parasitol. 2009, 121, 175-179. [CrossRef] 
23. Zhang, X.; He, C.C.; Liu, J.M.; Li, H.; Lu, K.; Fu, Z.Q.; Zhu, C.G.; Liu, Y.P.; Tong, L.B.; Zhou, D.B.; et al. Nested-PCR assay for detection of Schistosoma japonicum infection in domestic animals. Infect. Dis. Poverty 2017, 6, 86. [CrossRef] [PubMed]

24. Sun, K.; Xing, W.; Yu, X.; Fu, W.; Wang, Y.; Zou, M.; Luo, Z.; Xu, D. Recombinase polymerase amplification combined with a lateral flow dipstick for rapid and visual detection of Schistosoma japonicum. Parasit. Vectors 2016, 9, 476. [CrossRef]

25. Hung, Y.W.; Remais, J. Quantitative detection of Schistosoma japonicum cercariae in water by real-time PCR. PLoS Negl. Trop. Dis. 2008, 2, e337. [CrossRef]

26. Wang, C.; Chen, L.; Yin, X.; Hua, W.; Hou, M.; Ji, M.; Yu, C.; Wu, G. Application of DNA-based diagnostics in detection of schistosomal DNA in early infection and after drug treatment. Parasit. Vectors 2011, 4, 164. [CrossRef]

27. Xu, J.; Guan, Z.X.; Zhao, B.; Wang, Y.Y.; Cao, Y.; Zhang, H.Q.; Zhu, X.Q.; He, Y.K.; Xia, C.M. DNA detection of Schistosoma japonicum: Diagnostic validity of a LAMP assay for low-intensity infection and effects of chemotherapy in humans. PLoS Negl. Trop. Dis. 2015, 9, e0003668. [CrossRef] [PubMed]

28. Xu, J.; Rong, R.; Zhang, H.Q.; Shi, C.J.; Zhu, X.Q.; Xia, C.M. Sensitive and rapid detection of Schistosoma japonicum DNA by loop-mediated isothermal amplification (LAMP). Int. J. Parasitol. 2010, 40, 327-331. [CrossRef]

29. Xing, W.; Yu, X.; Feng, J.; Sun, K.; Fu, W.; Wang, Y.; Zou, M.; Xia, W.; Luo, Z.; He, H.; et al. Field evaluation of a recombinase polymerase amplification assay for the diagnosis of Schistosoma japonicum infection in Hunan province of China. BMC Infect. Dis. 2017, 17, 164. [CrossRef] [PubMed]

30. Weerakoon, K.G.; Gordon, C.A.; Gobert, G.N.; Cai, P.; McManus, D.P. Optimisation of a droplet digital PCR assay for the diagnosis of Schistosoma japonicum infection: A duplex approach with DNA binding dye chemistry. J. Microbiol. Methods 2016, 125, 19-27. [CrossRef] [PubMed]

31. Phuphisut, O.; Ajawatanawong, P.; Limpanont, Y.; Reamtong, O.; Nuamtanong, S.; Ampawong, S.; Chaimon, S.; Dekumyoy, P.; Watthanakulpanich, D.; Swierczewski, B.E.; et al. Transcriptomic analysis of male and female Schistosoma mekongi adult worms. Parasit. Vectors 2018, 11, 504. [CrossRef]

32. Nickel, B.; Sayasone, S.; Vonghachack, Y.; Odermatt, P.; Marti, H. Schistosoma mansoni antigen detects Schistosoma mekongi infection. Acta Trop. 2015, 141, 310-314. [CrossRef] [PubMed]

33. Vonghachack, Y.; Sayasone, S.; Khieu, V.; Bergquist, R.; van Dam, G.J.; Hoekstra, P.T.; Corstjens, P.L.A.M.; Nickel, B.; Marti, H.; Utzinger, J.; et al. Comparison of novel and standard diagnostic tools for the detection of Schistosoma mekongi infection in Lao People's Democratic Republic and Cambodia. Infect. Dis. Poverty 2017, 6, 127. [CrossRef] [PubMed]

34. Clerinx, J.; Cnops, L.; Huyse, T.; Tannich, E.; Van Esbroeck, M. Diagnostic issues of acute schistosomiasis with Schistosoma mekongi in a traveler: A case report. J. Travel Med. 2013, 20, 322-325. [CrossRef] [PubMed]

35. Khot, P.D.; Ko, D.L.; Hackman, R.C.; Fredricks, D.N. Development and optimization of quantitative PCR for the diagnosis of invasive aspergillosis with bronchoalveolar lavage fluid. BMC Infect. Dis. 2008, 8, 73. [CrossRef] [PubMed]

36. Frickmann, H.; Tenner-Racz, K.; Eggert, P.; Schwarz, N.G.; Poppert, S.; Tannich, E.; Hagen, R.M. Influence of parasite density and sample storage time on the reliability of Entamoeba histolytica-specific PCR from formalin-fixed and paraffin-embedded tissues. Diagn. Mol. Pathol. 2013, 22, 236-244. [CrossRef]

37. Bossuyt, P.M.; Reitsma, J.B.; Bruns, D.E.; Gatsonis, C.A.; Glasziou, P.P.; Irwig, L.; Lijmer, J.G.; Moher, D.; Rennie, D.; de Vet, H.C.W.; et al. STARD 2015: An updated list of essential items for reporting diagnostic accuracy studies. BMJ 2015, 351 , h5527. [CrossRef]

38. Zhang, Z.; Schwartz, S.; Wagner, L.; Miller, W. A greedy algorithm for aligning DNA sequences. J. Comput. Biol. 2000, 7, 203-214. [CrossRef]

39. Niesters, H.G. Quantitation of Viral Load Using Real-Time Amplification Techniques. Methods 2001, 25, 419-429. [CrossRef]

40. Zhou, L.; Tang, J.; Zhao, Y.; Gong, R.; Lu, X.; Gong, L.; Wang, Y. A highly sensitive TaqMan real-time PCR assay for early detection of Schistosoma species. Acta Trop. 2011, 120, 88-94. [CrossRef]

41. Hoffmann, T.; Hahn, A.; Verweij, J.J.; Leboulle, G.; Landt, O.; Strube, C.; Kann, S.; Dekker, D.; May, J.; Frickmann, H.; et al. Differing Effects of Standard and Harsh Nucleic Acid Extraction Procedures on Diagnostic Helminth Real-Time PCRs Applied to Human Stool Samples. Pathogens 2021, 10, 188. [CrossRef] [PubMed] 